\title{
Contribuições da carona solidária no processo de compartilhamento do conhecimento
}

\begin{abstract}
RESUMO
Atualmente, são mais de 85 milhões de carros no Brasil, que impactam a mobilidade de diversas cidades do País. Somado a este fato, questões relacionadas ao meio ambiente são de interesse crescente da sociedade, estimulando iniciativas como as caronas solidárias. Com o propósito de contribuir com a melhoria da mobilidade das cidades e reduzir impactos ao meio ambiente, diversas empresas aderiram à iniciativa. No entanto, pode-se formular uma questão de pesquisa que, eventualmente, poderia esclarecer melhor esta afirmativa, que pode ser caracterizada como uma tendência nas cidades mais inteligentes: "A carona solidária consiste apenas no compartilhamento do veículo? Ou se trata de algo mais?". A partir desta questão de pesquisa, o artigo teve como objetivo verificar os impactos da carona solidária para as organizações que a promovem, utilizando-se como referência a análise de caso de uma organização intensiva em conhecimento situada na cidade de Florianópolis - Santa Catarina. A metodologia segue uma abordagem predominantemente qualitativa, reunindo conceitos e princípios preliminarmente coletados, buscando-se compreender o fenômeno da carona solidária, utilizandose questionários e entrevistas semiestruturadas como instrumento de pesquisa. Complementarmente a pesquisa adota um tratamento de dados realizado quantitativamente, utilizando-se a bibliometria dos dados coletados na revisão de literatura realizada de forma sistemática. Não foram estabelecidos números mínimos nem máximos de colaboradores a serem entrevistados, pois foram todos voluntários a prestar mais informações acerca da iniciativa. Como resultado a pesquisa aponta que a carona solidária contribui na melhoria da autoestima, humor e qualidade de vida dos trabalhadores pelo compartilhamento de seus conhecimentos, além de impactar na organização, desenvolvendo relações profissionais e pessoais, melhoria da imagem organizacional e a melhoria da comunicação entre colaboradores que fortalecem a retenção de talentos nas organizações.
\end{abstract}

Palavras-chave: Gestão do conhecimento. Compartilhamento de conhecimento. Carona Solidária.

Paula Kaneoya Arasaki Mestranda em Engenharia e Gestão do Conhecimento Universidade Federal de Santa Catarina (UFSC) - Brasil phkaneoya@gmail.com

Caroline Cisne Doutoranda em Engenharia e Gestão do Conhecimento Universidade Federal de Santa Catarina (UFSC) - Brasil cs.cisne@gmail.com

Alexandre Ueno Doutorando em Engenharia e Gestão do Conhecimento Universidade Federal de Santa Catarina (UFSC) - Brasil alexandre.ueno@gmail.com

Neri dos Santos

Doutor em Ergonomie de I'Ingenierie Pontifícia Universidade Católica do Paraná (PUCPR) - Brasil nerisantos@gmail.com 


\section{INTRODUÇÃO}

Mesmo em uma economia do conhecimento, na qual o conhecimento é o fator de produção mais relevante e o seu compartilhamento agrega valor aos indivíduos e às organizações, o individualismo ainda persiste em determinados aspectos das relações humanas. Esse comportamento individualista pode ser evidenciado quando pensamos na mobilidade urbana, "marcada por uma crescente motorização individual" (BARCZAK; DUARTE, 2012, p. 14).

Esse comportamento gera prejuízos econômicos, sociais e ambientais para a sociedade, sendo necessária uma discussão sobre políticas de mobilidade urbana para amenizar a situação e promover o desenvolvimento sustentável. Porém, neste artigo não serão abordadas as questões pertinentes a uma política de mobilidade urbana, e sim uma iniciativa que vem sendo realizada por instituições públicas e privadas, que visam contribuir com uma solução simples para minimizar o problema do trânsito das cidades brasileiras: a carona solidária.

A carona solidária é uma prática que incentiva o compartilhamento de veículos, evitando o uso do carro por apenas um ocupante, sendo que duas ou mais pessoas que percorrem os mesmos trajetos, utilizem o mesmo veículo.

Sociedade e empresas têm estimulado as caronas, por meio de aplicativos, sites e incentivos, visando reduzir impactos ao meio ambiente, contribuir com a mobilidade das cidades e a qualidade de vida das pessoas e até mesmo gerar economia, ao dividir custos de trajetos (SHARECAR..., 2015; APLICATIVO..., 2015; JORDÃO, 2012). A adesão pode proporcionar uma maior interação entre os colaboradores, além de tornar a empresa mais sustentável.

No contexto de caronas solidárias promovidas pelas empresas, pode-se formular as seguintes questões de pesquisa: (i) A carona solidária é somente o compartilhamento do veículo? (ii) Quais são os impactos dessa iniciativa para a organização? (iii) Há alguma relação com a gestão do conhecimento? O artigo tem como objetivo principal analisar os impactos das iniciativas de carona solidária para as organizações que a promovem e verificar a relação com a gestão do conhecimento.

Ao proporcionar uma iniciativa como a Carona Solidária, uma organização pode incentivar práticas de gestão do conhecimento de uma maneira informal aos seus colaboradores, uma vez que a carona solidária proporciona um ambiente favorável ao compartilhamento e transferência de conhecimento. Dessa forma é preciso evidenciar se tais práticas realmente ocorrem.

\section{CARONA}

Atualmente, existem cerca de 85 milhões de carros circulando pelas ruas brasileiras. De acordo com dados do Anuário da Federação Nacional da Distribuição de Veículos Automotores (FENABRAVE, 2015), a média anual de emplacamentos de carros nos últimos cinco anos foi de 2,9 milhões.

Sendo um carro para cada 2,4 brasileiros - considerando a população de 204,7 milhões (IBGE, 2015), algumas cidades discutem questões relacionadas à mobilidade. É possível verificar aumento de iniciativas relativas ao uso de bicicletas nas cidades, pensando não somente na mobilidade, mas também no meio ambiente, ao contribuir com a redução de emissão de poluentes.

Neste contexto, surgem as caronas como forma de contribuir com a mobilidade urbana das cidades. De acordo com o Dicionário Michaelis, o termo 'carona' é definido por "condução ou transporte gratuito em qualquer veículo" (DICIONÁRIO..., 2015).

O tema tem obtido destaque na sociedade, por meio de diversas matérias que são veiculadas na mídia, esclarecendo e incentivando a prática, inclusive por meio de proposta de criação de Sistema Nacional de Transporte Solidário, que visa promover o compartilhamento de veículos particulares (BRASIL, 2014).

Esta temática está presente também em estudos científicos, que tratam desde o desenvolvimento de sistemas dinâmicos para a combinação de caronas e caroneiros (DIMITRAKOPOULOS; PANAGIOTIS; KOUTRA, 2012; YOUSAF et al, 2014), até a compreensão do assunto como transporte sustentável (SANTOS; BEHRENDT; TEYTELBOYM, 2010) e estudo de caso sobre aplicação de carona solidária em uma organização (OLIVEIRA, 2013).

Em iniciativas de carona promovidas pela sociedade, a internet possui papel fundamental. É por meio das mídias sociais, sites e aplicativos que as pessoas compartilham seus itinerários, se conhecem e se tornam parceiras de carona (MELHORES..., 2015). Em Florianópolis, Santa Catarina, a sociedade se mobilizou no período da greve do transporte público de 2013, e compartilhou itinerários nas mídias sociais para oferecer carona a quem necessitava (POPULAÇÃO..., 2013).

Mas não é apenas por meio das mídias sociais que caronas e caroneiros se conhecem. Santos, Behrendt 
e Teytelboym (2010) comentam da existência de caronas estabelecidas informalmente, como entre familiares, vizinhos e amigos, no qual ocorre revezamento para levar as crianças na escola, por exemplo. A colaboração e a 'troca de favores' se configuram como o benefício de quem participa desse tipo de carona.

No contexto das organizações, privadas ou públicas, podem ocorrer incentivos para os empregados compartilharem seus carros, sendo esta uma opção interessante para estimular a carona. Isto pois, existem alguns aspectos que dificultam a carona (SANTOS; BEHRENDT; TEYTELBOYM, 2010; OLIVEIRA, 2013):

- Inflexibilidade na viagem;

- Aumento do tempo de viagem;

- Perda de independência;

- Desinteresse; e outros.

Desta forma, os benefícios aos colaboradores consistem em uma forma de recompensá-los e, de certa forma, transpor barreiras ao não compartilhamento do veículo.

A carona como prática incentivada por organizações se torna interessante por alguns aspectos citados por Oliveira (2013, p. 70), que desenvolveu estudo de caso da carona solidária em uma instituição:

[...] a Carona Solidária é muito mais do que o uso compartilhado do automóvel. É um meio para que as pessoas criem vínculos e possam interagir de maneira mais amigável, ou seja, estar em contato com o outro. As pessoas tendem a conversar mais, contando suas histórias, angústias, problemas. Essa convivência diária poderá trazer com a companhia de outras pessoas, maior disposição para ao chegar ao seu destino, seja esse o trabalho ou a escola. Questões econômicas como dividir os gastos de gasolina, pedágio, entre outros, podem também vir a somar positivamente com o uso da carona.

A partir desses aspectos, verifica-se que a carona solidária impacta em:

- Qualidade de vida;

- Relacionamento entre as pessoas;

- Questão financeira.

Desta forma, sendo uma iniciativa que impacta no relacionamento entre as pessoas, tornando os vínculos mais fortes, a carona solidária se relaciona com a gestão do conhecimento nas organizações, a partir do momento em que impacta na comunicação e confiança entre as pessoas, aspectos relacionados ao compartilhamento de conhecimento (NONAKA; TAKEUCHI, 1997).

\section{GESTÃO DO CONHECIMENTO}

A carona solidária se relaciona com a gestão do conhecimento em alguns aspectos, como: as organizações intensivas em conhecimento, o ambiente BA e o modelo SECI de conversão do conhecimento.

\subsection{Organizações intensivas em conhecimento}

Organizações intensivas em conhecimento são aquelas que possuem atividades de natureza cognitiva, cujo conhecimento se torna fator de produção (SILVA, 2010). Os ativos intangíveis são valiosos, incorporados nas competências de cada indivíduo e utilizados em prol da organização (PROBST; RAUB; ROMHARDT, 2002).

Sveiby (2001) propõe nove formas básicas de transferência de conhecimento para criar valor para as organizações:

- Entre indivíduos: consiste em prover uma melhor comunicação entre colaboradores de uma organização;

- $\quad$ Entre indivíduos para a estrutura externa: consiste em identificar como os colaboradores de uma organização transferem conhecimentos para o mundo externo;

- Entre a estrutura externa para indivíduos: está relacionada ao como os empregados podem aprender com a estrutura externa;

- Entre a competência para a estrutura interna: consiste em identificar como melhorar a conversão da competência individual para sistemas, ferramentas e templates;

- Entre a estrutura interna para a competência individual: está relacionado a atividades focadas em meIhorar a interface de sistemas entre computadores e humanos, processos de aprendizado baseados em ações, simulações e ambientes interativos de e-learning;

- Entre estrutura externa: está relacionada a atividades focadas na parceria e alianças, melhorando a imagem da organização e o equilíbrio da marca de produtos e serviços;

- $\quad$ Entre a estrutura externa para interna: se refere ao conhecimento que a organização pode obter a partir do mundo externo e como o aprendizado pode ser convertido em ação; 
- Entre estrutura interna: está relacionada a atividades focadas na construção de sistemas de TI integrados, melhorar o layout do escritório, entre outros.

Entre essas formas, destaca-se a transferência de conhecimento entre indivíduos por se relacionar com o tema da carona solidária. Esse tipo de transferência está relacionado à melhoria da comunicação entre colaboradores, de forma a contribuir com a transferência de competências entre pessoas em uma organização, o que impacta na criação de valor organizacional. O principal desafio acerca desse tipo de transferência é a construção de confiança e a propensão ao compartilhamento de conhecimentos (SVEIBY, 2001).

\subsection{Ambiente $B a$}

A criação de um ambiente propício ao compartilhamento de conhecimento - o conceito de $B a$ - corrobora com o relacionamento entre colaboradores, construção de confiança (TAKEUCHI; NONAKA, 2008) e contribui para a transferência de competências, mencionada por Sveiby (2001).

O Ba é um conceito criado pelo filósofo japonês Kitaro Nishida (1921-1970), que pode ser definido por espaço compartilhado - que pode ser físico, mental ou virtual - que suporta a criação de conhecimento (TAKEUCHI; NONAKA, 2008).

As relações proporcionadas pelo ambiente $B a$ possibilitam o compartilhamento de experiências entre os trabalhadores do conhecimento, que se relacionam com a conversão do conhecimento, conforme a Figura 1.

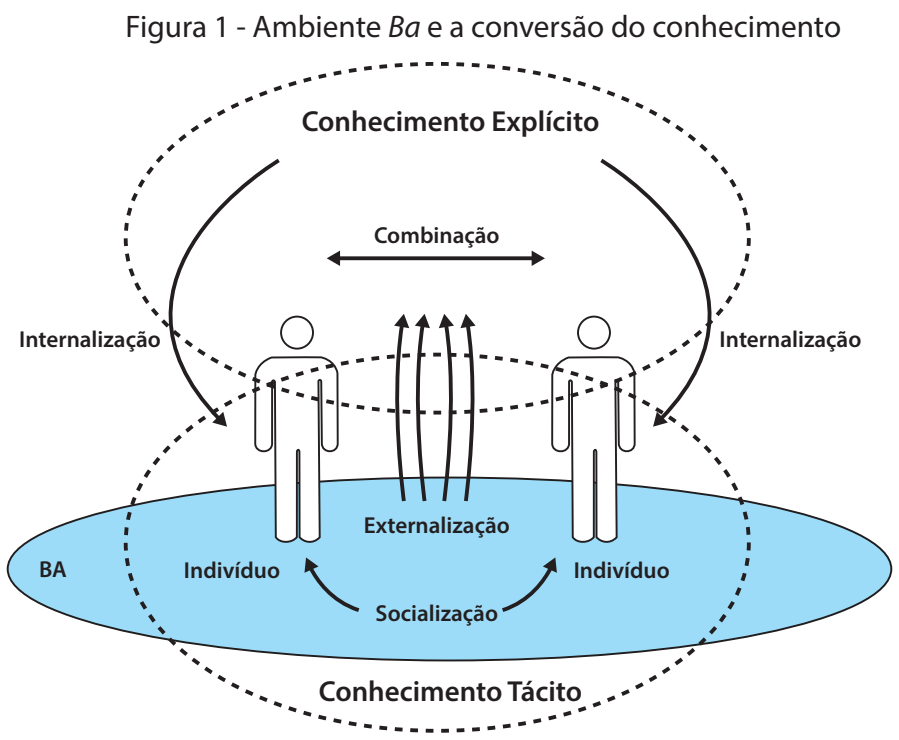

Fonte: Adaptado de Nonaka e Konno (1998, p. 44)

O ambiente $B a$ suporta o compartilhamento de experiências e conhecimentos tácitos entre indivíduos, por meio da socialização dos conhecimentos. Os conhecimentos tácitos que são socializados podem, em parte, serem explicitados, por meio da externalização dos conhecimentos, tornando-se conhecimentos explícitos. Os conhecimentos que foram explicitados podem ser combinados com outros conhecimentos explícitos disponíveis e, então, ocorre a combinação dos conhecimentos compartilhados, que podem ser internalizados pelos indivíduos, tornando-se novamente em conhecimentos tácitos, originando-se assim uma espiral virtuosa do conhecimento (NONAKA; KONNO, 1998).

\subsection{Compartilhamento de conhecimento}

O destaque aos aspectos relacionados ao compartilhamento de conhecimentos ocorre, pois o conhecimento quando compartilhado se torna crescente na medida em que o indivíduo compartilha (TIWANA, 2002). De acordo com Wilson, Goodman e Cronin (2007), o conhecimento compartilhado se caracteriza quando os conhecimentos são distribuídos e entendidos por todos os membros de um grupo, neste caso, esse processo ocorre diariamente nas organizações, sendo um processo fundamental para a tomada de decisão.

Nonaka e Takeuchi (1997) explicam que o conhecimento organizacional ocorre a partir de possíveis interações entre os conhecimentos explícito (de fácil transmissão e codificação) e tácito (pessoal e de difícil transmissão). O conhecimento tácito está incorporado na experiência dos indivíduos, atrelado a fatores intangíveis, como crenças, emoções, habilidades e outros aspectos. Trata-se de ativo de importância para as organizações 
do conhecimento. Enquanto que o conhecimento explícito é transmitido com facilidade, pois está registrado em algum suporte, como um manual ou sistema, por exemplo.

As interações entre esses dois tipos de conhecimento ocorrem por meio da conversão do conhecimento, a partir do modelo SECl: socialização, externalização, combinação e internalização.

Segundo Nonaka e Takeuchi (1997), o conhecimento é compartilhado, comunicado, padronizado e internalizado pelos membros de uma organização, visando à criação de novos conhecimentos.

Figura 2 - Modelo SECl: conversão do conhecimento

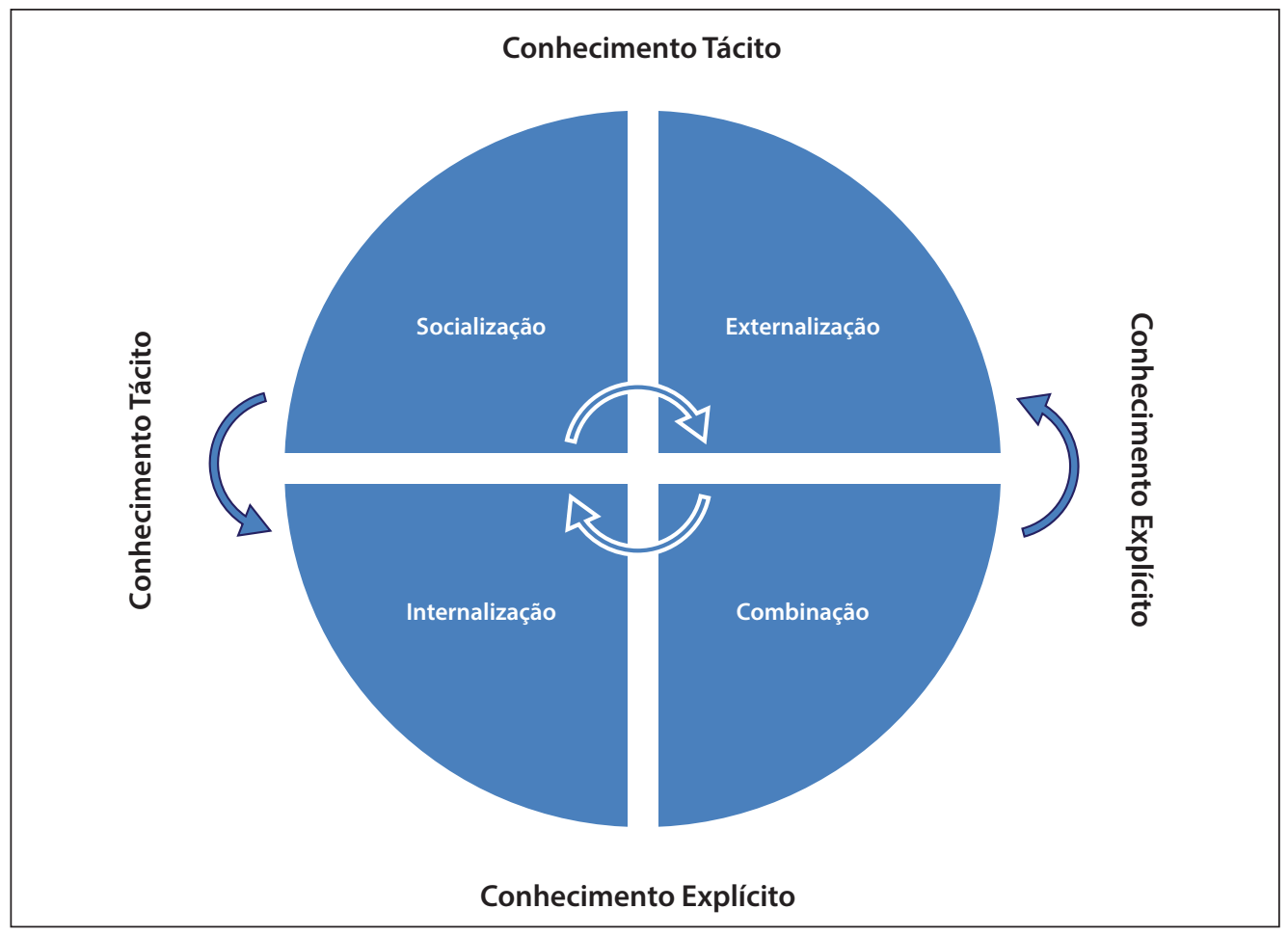

Fonte: Adaptado de Nonaka e Takeuchi (1997, p. 80)

O modelo SECl, de conversão do conhecimento, consiste em:

- Socialização: conversão de conhecimento tácito em conhecimento tácito, por meio do compartilhamento de experiências, por exemplo;

- Externalização: conversão do conhecimento tácito em explícito, utilizando palavras, imagens, dedução, indução, abdução;

- Combinação: sistematização e relação de conhecimentos explícitos, codificando documentos;

- Internalização: conversão do conhecimento explícito em tácito, por meio do compartilhamento com outros indivíduos, dando origem a nova espiral do conhecimento.

A criação de novos conhecimentos é estimulada por organizações, por estar relacionada à competitividade e capacidade de inovar nos negócios. Neste contexto, são diversas as empresas que atentam à gestão do conhecimento.

A Gestão do Conhecimento pode ser entendida como um processo de identificação, criação e aplicação dos conhecimentos de uma organização, de maneira que esta faça o gerenciamento dos seus ativos de conhecimento, com o objetivo de proporcionar tomadas de decisão assertivas para promover uma vantagem competitiva no seu mercado de atuação (NONAKA; TAKEUCHI, 1997).

Assim, o papel da Gestão do conhecimento na sociedade atual é de auxiliar as organizações a estarem preparadas para a economia do conhecimento, tendo como ativo vital o conhecimento.

\section{PROCEDIMENTOS METODOLÓGICOS}

Os procedimentos metodológicos adotados nesta pesquisa compreendem uma revisão de literatura realizada de forma sistemática, a aplicação de um questionário semiestruturado e a realização de entrevistas. 


\subsection{Revisão de literatura}

Para o desenvolvimento do estudo, foi realizada uma revisão de literatura nas bases de dados do Periódicos Capes (que engloba a Web of Science e a Scopus) e Scielo realizadas de forma sistemática.

Os termos de busca utilizados foram definidos segundo uma estratégia de busca que permitiu recuperar documentos que representassem o contexto da carona solidária, colaboração e gestão do conhecimento. Assim, o Quadro 1 tem por objetivo demonstrar os resultados encontrados:

Quadro 1 - Resultado de busca em base de dados

\begin{tabular}{|l|c|c|c|}
\hline \multicolumn{1}{|c|}{ TERMO } & CAPES & SCIELO & SELECIONADOS \\
\hline $\begin{array}{l}\text { ("car pool" OR "ride sharing") AND } \\
\text { "knowledge sharing" }\end{array}$ & 25 & 0 & 4 \\
\hline $\begin{array}{l}\text { ("car pool" OR "ride sharing") AND } \\
\text { "knowledge management" }\end{array}$ & 9 & 0 & 0 \\
\hline $\begin{array}{l}\text { ("car pool" OR "ride sharing") AND } \\
\text { collaboration AND organization OR } \\
\text { company OR enterprise }\end{array}$ & 1.038 & 0 & 0 \\
\hline carona AND "gestão do conhecimento" & & 0 & 0 \\
\hline $\begin{array}{l}\text { carona AND "compartilhamento de } \\
\text { conhecimento" }\end{array}$ & 13 & 0 & 0 \\
\hline $\begin{array}{l}\text { carona AND colaboração AND } \\
\text { organização OR empresa }\end{array}$ & 4 & 0 & 0 \\
\hline \multicolumn{1}{c|}{ TOTAL } & 53 & 0 & 4 \\
\hline
\end{tabular}

Fonte: os autores (2015)

Nos dois primeiros termos não foram aplicados filtros de busca das palavras somente no título ou no assunto, pois são poucos os estudos que relacionam os dois temas. A exemplo, buscando somente em assunto, o primeiro termo não recupera documento algum. Sendo assim, a seleção dos artigos foi por meio do conteúdo apresentado relacionado com os temas, seja simultaneamente ou não.

Já o terceiro termo ("car pool" OR "ride sharing") AND collaboration AND organization OR company OR enterprise recuperou mais de mil resultados, o que requereu o estabelecimento de critérios para realizar a seleção dos estudos relevantes ao tema:

- ao inserir como critério o aparecimento dos termos no campo "assunto", foram recuperados 4 documentos, descartados por irrelevância ao estudo;

- ao inserir como critério o aparecimento dos termos no campo 'título', foram recuperados 22 documentos, no qual diversos eram artigos de jornal comentando sobre empresas como Uber, que oferece aplicativo para sistema de caronas remuneradas - que foge do escopo do trabalho, e que portanto foram descartados. Utilizou-se o critério de documentos 'somente artigos', e obteve-se 6 resultados, todos descartados por irrelevância ao estudo (relação entre carona, colaboração e organizações.

A busca pelos termos "carona AND 'gestão do conhecimento"' e "carona AND 'compartilhamento de conhecimento'" recuperou 17 resultados, dos quais nenhum apresentou relação entre a iniciativa de carona e a gestão ou compartilhamento do conhecimento.

O último termo recuperou 53 documentos e, com o objetivo de selecionar os estudos mais relevantes para a pesquisa, inseriu-se como critério a busca do termo somente no assunto, no entanto, não foram recuperados documentos. Ao limitar a busca do termo ao título, foram recuperados 2 documentos, descartados por irrelevância ao estudo. Os demais termos recuperaram poucos documentos, conforme o quadro apresentado, o que possibilitou a seleção dos documentos, sem inserção de qualquer critério.

A fim de complementar a revisão sistemática, foram verificados conteúdos de autores da área de gestão do conhecimento e conhecimento organizacional.

\subsection{Estudo de caso}

Para a seleção da empresa algumas informações foram levadas em consideração:

- $\quad$ O Sudeste é a região que mais possui carros, com 42,7 milhões; seguida pela região Sul, com 17,3 milhões de carros (FENABRAVE, 2015); 
- Apesar de ser a segunda região com mais carros, ao relacionar esse número com o de habitantes, a região Sul é a que mais possui carros por habitante. Ou ainda, é a região com menos ocupantes por carro, sendo um veículo para cada 1,66 habitante, em contraste com 1,99 habitante por carro da região Sudeste (Apêndice $A$ );

- Neste contexto, o estado de Santa Catarina, apesar de ser o menos populoso - 6,7 milhões (IBGE, 2014) - e com menor número de carros na região Sul - 4,4 milhões (FENABRAVE, 2015) -, é o estado com mais carros por habitante. Ou ainda, o estado com menor número de ocupantes por carro no País, com 1,47 habitante por veículo (Apêndice A);

- Somado a isso, Santa Catarina é o estado da região Sul que mais possui habitantes por $\mathrm{km}^{2}-65,27$ habitantes por km² (IBGE, 2015) - e carros em uma mesma área - 46,44 carros por km² (Apêndice A);

A partir da análise desses fatores, optou-se por Santa Catarina por ser um estado que se destaca em relação à proporção de habitantes por carro - sendo o estado com menor número de ocupantes por veículo no País - e também na proporção de carros por $\mathrm{km}^{2}$, o que impacta em questões de mobilidade.

Dentre as cidades catarinenses, a selecionada para o estudo foi Florianópolis (SC), por se tratar da capital do Estado, e que apresenta diversos problemas de mobilidade. Sendo assim, a Carona Solidária surge como uma tentativa promovida pela sociedade e por empresas da região para contribuir com a melhoria da mobilidade na cidade.

\subsubsection{Questionário}

Foi desenvolvido um questionário com nove perguntas - sendo quatro fechadas e cinco abertas -, com o objetivo de identificar o perfil do colaborador (caroneiro ou carona), sua motivação e demais questionamentos.

O questionário foi desenvolvido com base na revisão de literatura relacionando os termos de busca e instrumentalizado na ferramenta de Formulários Google e divulgado na mídia social corporativa, meio utilizado pela organização para comunicações e compartilhamento de informações e conhecimentos. Os participantes da iniciativa Carona Solidária e interessados no estudo contribuíram de forma voluntária com a resposta ao questionário'.

As respostas às perguntas fechadas foram tratadas de forma estatística, gerando gráficos para facilitar a visualização e análise dos dados, a fim de delinear o perfil dos participantes. Já as respostas às perguntas abertas foram inseridas em um documento e categorizadas em acordo com aspectos relativos ao estudo, como a opinião do participante quanto à iniciativa, sua motivação e demais informações.

O último questionamento presente no instrumento de coleta de dados era o interesse do respondente em participar do estudo, por meio de uma entrevista. A partir desse espaço destinado para a manifestação dos respondentes, que foram obtidos os participantes da etapa de entrevista.

\subsubsection{Entrevistas}

As entrevistas eram de roteiro semiestruturado, com cinco ou seis perguntas, dependendo do perfil do entrevistado. O processo de entrevistas ocorreu em acordo com os preceitos éticos previstos na Resolução $\mathrm{n}$. 466/2012, do Conselho Nacional de Saúde (BRASIL, 2012). Para tanto, as entrevistas foram realizadas em salas separadas do ambiente de trabalho - a fim de que o meio não interfira nas respostas - e gravadas sob a autorização dos participantes, obtida por meio de concessão antes da entrevista e reforçada por meio de um Termo de Consentimento assinado por ambas as partes.

Para esta etapa, a fim de obter uma visão geral da iniciativa, entrevistou-se os seguintes perfis:

- Gerente do núcleo de gestão de pessoas, a fim de ter uma visão da organização em relação à Carona Solidária;

- Colaboradores que dão carona, para compreender o que lhes motiva a participar e verificar as impressões acerca da iniciativa;

- Colaboradores que recebem carona, para verificar as impressões acerca da iniciativa.

Por se tratar de uma etapa secundária, nos quais somente os respondentes dos questionários que estivessem interessados em colaborar com o estudo seriam os que concederiam entrevistas, não houve delimitação de número mínimo e máximo de participantes. Ao final do questionário aplicado, foi inserido um campo para informar o contato, caso tivesse disponibilidade para contribuir com a etapa de entrevista do estudo. Cinquen-

1 Disponibilizado no endereço eletrônico:

https://docs.google.com/forms/d/1BMFI9_irOjnlm4HA6zfZzJQirVCnzmNOnR17zG_sGKc/viewform 
ta por cento dos colaboradores que responderam o questionário foram entrevistados, ou seja, dez colaboradores responderam ao questionário e cinco participaram da entrevista.

Após a realização das entrevistas, as gravações foram transcritas, inseridas em um documento único e analisadas. As falas dos entrevistados foram categorizadas por temas que posteriormente deram origem às seções do presente artigo, como: impactos da iniciativa na organização e na vida dos colaboradores, o relacionamento entre os participantes e demais categorias. Com base nos dados coletados por meio dos questionários e das entrevistas, foi realizada a análise do estudo de caso.

O estudo de caso foi realizado em uma organização intensiva em conhecimento de Florianópolis (SC). Trata-se de uma holding que atua com atividades voltadas para o mercado digital e que promove a Carona Solidária entre colaboradores. Sua iniciativa foi divulgada na mídia, o que possibilitou a identificação da organização como possível objeto do estudo de caso. A empresa em questão possui como um dos seus valores: "Respeitamos as pessoas, as instituições e o meio ambiente".

Dessa forma, as pessoas são importantes para a instituição e para demonstrar esse valor a holding investiu em um espaço físico que contribui para o ambiente de interação entre colaboradores e consequentemente a troca de conhecimentos. O fato de a empresa ter sido premiada pelo Great Place to Work como uma das melhores empresas para se trabalhar no Brasil no ano de 2014 é um indício de uma gestão que prioriza o desenvolvimento humano e também organizacional.

\section{ANÁLISE}

Os dados para a pesquisa foram coletados no formato de questionário, e em um segundo momento, por meio de entrevista aos colaboradores que se voluntariaram para tal. As subseções a seguir foram definidas segundo os objetivos da pesquisa, reunindo os resultados obtidos nas entrevistas, questionários e revisão de literatura.

\subsection{Motivação e conhecimento da iniciativa}

A pesquisa contou com a adesão de dez colaboradores, que de forma voluntária responderam ao questionário. Entre as pessoas que responderam o questionário, $80 \%$ eram colaboradores que davam carona, sendo que a principal motivação para participação da iniciativa está relacionada à colaboração. Dentre esses, 87,5\%, disseram não se importar em levar um colega de trabalho que vai para a mesma região de destino. Em segundo lugar na motivação (75\%) esteve o benefício de estacionamento gratuito oferecido pela empresa. Apesar da gratuidade do estacionamento ser um fator importante na carona solidária, $25 \%$ dos respondentes concedem carona, mesmo sem ter direito ao benefício ainda.

Tal informação está em acordo com a importância de se oferecer benefícios aos colaboradores que dão carona, como forma de recompensar alguns aspectos que essa prática envolve como, por exemplo, a perda de independência e o compromisso que isso requer (SANTOS; BEHRENDT; TEYTELBOYM, 2010).

Os colaboradores têm conhecimento da iniciativa por meio de diversos canais e momentos: em reunião geral, pelo núcleo de gestão de pessoas, por colegas de trabalho, e até mesmo no momento da entrevista de recrutamento.

\subsection{Relacionamento entre participantes}

O núcleo de gestão de pessoas da organização e o grupo da Carona Solidária na mídia social corporativa auxiliam os colaboradores a encontrarem sua carona ou caroneiro na empresa utilizada como estudo de caso. No entanto, $60 \%$ conseguiram por conta própria, em conversas informais de trabalho, ou por fazer parte da mesma equipe. Os outros $40 \%$ foram por meio da própria iniciativa, ou por indicação do núcleo ou de colegas de trabalho.

Geralmente, os colaboradores que compartilham o veículo são da mesma área de negócio ( $90 \%$ das respostas), dentre as diversas que compõem a holding. No entanto, existem casos de colaboradores que participam da Carona Solidária e que são de diferentes empresas. A iniciativa aproximou colaboradores que, se não fosse pela ação, não teriam contato que fosse além dos encontros de corredor.

A carona possibilita a comunicação entre colaboradores de diferentes funções na organização, englobando estagiários, analistas, líderes e gestores das áreas de negócio. Apesar de envolver diferentes níveis hierárquicos da organização, conforme relato de entrevistado, não há qualquer diferenciação devido a esse fato, seja no trato ou nos temas das conversas que acontecem durante o trajeto da carona.

A partir dos dados de que $30 \%$ das pessoas que responderam ao questionário afirmaram trabalhar no 
mesmo projeto e $30 \%$ disseram sentar próximos às caronas ou caroneiros, é possível supor que a iniciativa:

- $\quad$ Fortalece e cria novas relações entre colaboradores de diferentes empresas, áreas de negócios ou projetos;

- Contribui para que os colaboradores conheçam as outras empresas da holding e seus negócios, de forma a resultar em uma visão global da organização;

- Corrobora com insights, novas ideias e melhorias na organização, a partir de conversas e compartilhamento de conhecimentos entre pessoas de diferentes visões do negócio; entre outros.

Questionados se a Carona Solidária consiste somente no compartilhamento do veículo, 90\% dos respondentes afirmaram que a iniciativa vai além, o que está em acordo com Oliveira (2013), conforme Quadro 2.

Quadro 2 - Carona Solidária: além do veículo

\begin{tabular}{|l|c|}
\hline \multicolumn{1}{|c|}{ RESPOSTAS } & OCORRÊNCIA \\
\hline $\begin{array}{l}\text { Cria vínculos de amizade, compartilhamento de momentos, aproximação entre } \\
\text { as pessoas }\end{array}$ & $50 \%$ \\
\hline Troca de ideias, informações e experiências profissionais & $20 \%$ \\
\hline É mais que o compartilhamento do veículo, mas não especificou & $20 \%$ \\
\hline Outros & $10 \%$ \\
\hline
\end{tabular}

Fonte: os autores (2015)

A partir das respostas dadas, é possível verificar a percepção dos colaboradores quanto à iniciativa e as relações de trabalho. A Carona Solidária possibilita o compartilhamento de informações, ideias, conhecimentos e experiências entre carona e caroneiro, bem como cria e fortalece laços de amizade entre colaboradores.

\subsection{Impactos da carona na vida dos colaboradores}

A promoção da Carona Solidária por uma organização gera impactos na vida dos colaboradores, que vai além da mudança de rotina e perda da independência (SANTOS; BEHRENDT; TEYTELBOYM, 2010). Com base nas entrevistas realizadas, pode-se agrupar o resultado da análise definindo que $20 \%$ abordaram a disposição, $20 \%$ comentaram da autoestima, 100\% afirmaram que afeta a saúde psicológica, $60 \%$ citaram a melhora no humor e o impacto na qualidade de vida foi mencionada por $40 \%$ dos entrevistados. Sendo assim, a Carona Solidária afeta em:

- Disposição: no Brasil, o transporte público ainda não é tão eficiente e de qualidade, se comparado com o carro particular. Muitas vezes, as pessoas enfrentam ônibus cheios, que param em cada ponto, disputam as ruas com os veículos particulares, e que como consequência, demoram a chegar no destino. Receber a carona impacta na redução do tempo de transporte, o que aumenta o tempo de descanso de quem antes se locomovia pelo transporte público. Esse descanso contribui para uma melhor disposição para o trabalho, impactando na produtividade dos colaboradores;

- Autoestima: assim como o tempo para descanso e a disposição aumentam, a autoestima também aumenta. Ter o conforto do carro, saber que não irá percorrer o trajeto até o trabalho de pé em um ambiente cheio e, por vezes, enclausurado, impacta na forma como as pessoas se apresentam no trabalho, por meio de roupas, sapatos e maquiagens. Além disso, o fato de impactar positivamente na vida de outras pessoas, a partir da carona, surte efeitos na autoestima do caroneiro, que se sente bem sabendo que está ajudando os colegas de trabalho;

- Saúde psicológica: a carona é compartilhar o veículo, ideias, experiências, momentos, sentimentos e frustrações, sejam pessoais ou profissionais. O estresse do trânsito da cidade é minimizado quando há alguém no carro para conversar, as ansiedades e frustrações do trabalho são extravasadas no momento da carona, impactando nas relações de família, que estão externas ao contexto profissional. Diversos são os aspectos que relacionam a carona à saúde psicológica das pessoas.

- Humor: assim como a saúde psicológica, a carona afeta o humor das pessoas. Conversar com amigos no caminho do trabalho afeta o humor e a disposição para o trabalho, de acordo com um dos entrevistados.

- Qualidade de vida: a carona afeta compromissos que vão além do trabalho, como o exemplo de um dos entrevistados que reside próximo à universidade e dá carona a pessoas que estudam. Receber a carona possibilita chegar no compromisso no horário, sem preocupação de ter que se estender um pouco no trabalho, e economizando o tempo de trajeto entre os pontos. 


\subsection{Impactos da carona à organização}

Os impactos da promoção da carona solidária na organização são diversos, conforme verificado nas respostas ao questionário e nas entrevistas realizadas:

- Desenvolvimento de relações profissionais e pessoais: além da amizade que a convivência pode criar, os relacionamentos profissionais também são desenvolvidos. A convivência facilita a comunicação, possibilita conhecer a outra pessoa, inclusive a função que desempenha na organização, o que contribui para saber a quem recorrer na organização, quando tiver alguma dificuldade relacionada à atividade dessa pessoa;

- Melhoria da imagem da organização: a promoção da Carona Solidária foi relacionada à preocupação da organização com os colaboradores, sendo um aspecto que agrega valor à imagem da empresa ante seus colaboradores. E essa boa imagem não se limita aos colaboradores. Um dos entrevistados mencionou que divulgou a iniciativa para amigos e familiares, a fim de incentivar a promoção da Carona Solidária em outras organizações;

- Desenvolvimento de senso colaborativo na organização: a Carona Solidária é movida por meio da colaboração entre os funcionários. A partir de um incentivo, a colaboração é estimulada, mas não se limita à iniciativa. Trata-se apenas de uma iniciativa que promove esse comportamento na organização, que também corrobora com a redução ou eliminação de duas das quatro barreiras à colaboração nas organizações: barreira de retenção, no qual as pessoas não estão dispostas a contribuir; e barreira de transferência, em que as pessoas não conseguem trabalhar com quem não conhecem (HANSEN, 2010);

- Melhoria da qualidade de vida dos colaboradores: conforme relatado na seção anterior, os benefícios da Carona Solidária para a qualidade de vida dos colaboradores são diversos;

- Melhoria da comunicação entre colaboradores: a convivência diária afeta a comunicação entre colaboradores, seja pela facilidade em explicitar fatos e experiências, por exemplo, ou pelo conhecimento de como o outro se comunica, o que contribui para a compreensão entre as partes;

- Disseminação do modelo mental e visão compartilhada da organização: dentre os assuntos conversados durante o trajeto entre a empresa e a casa, as pessoas que compartilham o mesmo veículo tendem a conversar sobre o trabalho. Apesar de não ter sido mencionado como tema principal, eventualmente, fatos que ocorrem na organização são os assuntos das conversas. Colaboradores novos questionam determinadas atitudes, comportamentos e políticas da organização, enquanto que os mais antigos acabam por sanar as dúvidas, e de forma a disseminar o modelo mental e a replicar a visão compartilhada da organização;

- Geração de insights e impactos na produtividade: conversar com colaboradores de outras áreas de negócios, outras funções, ou mesmo com o que atua em mesmo projeto, porém fora do ambiente de trabalho, pode contribuir para a geração de insights, ideias e gerando inovação para a organização. Um dos entrevistados mencionou que acontecem situações em que se conversa sobre trabalho com o caroneiro, em que pensam conjuntamente em soluções para serem postas em prática no dia seguinte, o que impacta na motivação em relação ao trabalho e também na produtividade dos colaboradores;

- Desenvolvimento de confiança entre colaboradores: a convivência diária, ou frequente, fortalece as relações pessoais e profissionais, melhora a comunicação entre as pessoas e também corrobora com o desenvolvimento da confiança, o que impacta no próximo aspecto, do compartilhamento de conhecimentos;

- Compartilhamento de conhecimentos: a partir de ambiente propício (ambiente $\mathrm{Ba}$ ), da confiança construída e das relações estabelecidas, o compartilhamento de conhecimento entre os colaboradores é facilitado. A falta de confiança e de tempo, barreiras para o compartilhamento do conhecimento, são eliminados ou reduzidos com iniciativas como a Carona Solidária;

- Melhoria do clima organizacional: a partir da criação e fortalecimento das relações a partir da iniciativa, o clima organizacional é impactado. São diversos colaboradores que participam da iniciativa e que, por sua característica e benefícios, acabam por incorporar um perfil mais colaborativo e saudável, impactando na melhoria do clima organizacional.

Estes foram alguns dos impactos que a Carona Solidária pode gerar se implantada em uma organização, a partir da análise do estudo de caso. Alguns desses aspectos se relacionam com a retenção de talentos, para o qual Martins (2014) recomenda ações organizacionais, como:

- Criação de ações organizacionais, que estimulem a interação entre colaboradores, e impactem na melhoria do clima organizacional;

- Criação de ambiente familiar, a partir de promoção de confraternizações e estimulando o colabora- 
dor a contribuir com um ambiente mais acolhedor;

- Criação de oportunidades para o compartilhamento de ideias e experiências.

\subsection{Carona e gestão do conhecimento}

A Carona Solidária se relaciona à gestão do conhecimento, principalmente em relação ao compartilhamento do conhecimento. Segue quadro que relaciona os atritos, ou barreiras, à transferência de conhecimentos (DAVENPORT; PRUSAK, 2003) e as contribuições da Carona Solidária para isso (Quadro 3).

Quadro 3 - Atritos e contribuições da Carona Solidária

\begin{tabular}{|c|c|}
\hline ATRITO & CARONA SOLIDÁRIA \\
\hline Falta de confiança mútua & $\begin{array}{l}\text { A partir da convivência diária ou frequente, que a Carona Solidária } \\
\text { proporciona, relacionamentos são construídos, bem como a confiança entre os } \\
\text { colaboradores. A partir da confiança mútua, a transferência de conhecimentos } \\
\text { entre indivíduos é facilitada, de forma a criar valor organizacional (SVEIBY, } \\
\text { 2001). }\end{array}$ \\
\hline $\begin{array}{l}\text { Diferentes culturas, } \\
\text { vocabulários e quadros de } \\
\text { referência }\end{array}$ & $\begin{array}{l}\text { A Carona Solidária facilita a comunicação entre colaboradores, assim como a } \\
\text { explicitação e transferência de conhecimentos (NONAKA;TAKEUCHI, 1997). } \\
\text { A partir da comunicação, ocorre a criação de significados entre membros de } \\
\text { uma organização, o que está relacionado à construção de conhecimentos e } \\
\text { tomada de decisão (CHOO, 2003). Ela se relaciona à disseminação de modelos } \\
\text { mentais e criação de visão compartilhada, duas das cinco disciplinas que } \\
\text { orientam as organizações que aprendem (SENGE, 2008). } \\
\text { A barreira é transposta a partir da comunicação estabelecida entre os } \\
\text { colaboradores, no qual percepções são explicitadas por funcionários mais } \\
\text { recentes na empresa, e o modelo mental organizacional é explicado pelo } \\
\text { colaborador antigo e compreendido pelo novo. Neste contexto, como tempo, } \\
\text { os modelos mentais, comportamentos, culturas e demais aspectos dos } \\
\text { colaboradores da organização passam a se alinhar. }\end{array}$ \\
\hline $\begin{array}{l}\text { Falta de tempo e de locais } \\
\text { de encontro; ideia estreita } \\
\text { de trabalho produtivo }\end{array}$ & $\begin{array}{l}\text { A Carona Solidária proporciona tanto tempo, quanto local para o } \\
\text { compartilhamento de ideias, experiências e conhecimentos. O ambiente } \\
\text { proporcionado pela iniciativa é criado pelos colaboradores e é propício à } \\
\text { transferência de conhecimentos (ambiente Ba). Além disso, o tempo do trajeto } \\
\text { entre empresa e casa é utilizado para conversar sobre assuntos que durante o } \\
\text { expediente não foi possível, conforme relato de um dos entrevistados. }\end{array}$ \\
\hline $\begin{array}{l}\text { Falta de capacidade de } \\
\text { absorção pelos recipientes }\end{array}$ & $\begin{array}{l}\text { A conversa entre colaboradores de diferentes projetos, áreas de negócios, ou } \\
\text { mesmo percepções contribui para a obtenção de diferentes pontos de vista e } \\
\text { opiniões acerca de assuntos e atividades. Obter um ponto de vista diferenciado } \\
\text { pode contribuir para a geração de novas ideias, a motivação dos colaboradores } \\
\text { e, a consequente, inovação organizacional. }\end{array}$ \\
\hline $\begin{array}{l}\text { Crença de que o } \\
\text { conhecimento é } \\
\text { prerrogativa de } \\
\text { determinados grupos, } \\
\text { síndrome do "não } \\
\text { inventado aqui" }\end{array}$ & $\begin{array}{l}\text { A Carona Solidária viabiliza o contato e relacionamento entre colaboradores de } \\
\text { diferentes projetos, áreas de negócios, empresas e nível hierárquico. Conforme } \\
\text { relatado por entrevistado, ocorrem situações em que a carona é fornecida ao } \\
\text { estagiário e ao gestor e, no entanto, não há diferenciação no comportamento } \\
\text { e nos assuntos tratados. A titulação perde valor na iniciativa, democratizando } \\
\text { o compartilhamento das ideias e do conhecimento. }\end{array}$ \\
\hline $\begin{array}{l}\text { Intolerância com erros ou } \\
\text { necessidade de ajuda }\end{array}$ & $\begin{array}{l}\text { A partir da iniciativa, desenvolve-se um perfil mais colaborativo nos indivíduos, } \\
\text { considerando os impactos positivos que a Carona Solidária possui na vida das } \\
\text { pessoas e a imagem que elas passam a ter em relação à organização. Tal perfil se } \\
\text { relaciona com pessoas mais solícitas, proativas, colaborativas, o que corrobora } \\
\text { com a redução ou eliminação de comportamentos como intolerâncias aos } \\
\text { erros. }\end{array}$ \\
\hline
\end{tabular}

Fonte: os autores (2015), adaptado de Davenport e Prusak (2003) 
Além das contribuições em relação aos atritos ou barreiras à transferência de conhecimentos, a Carona Solidária se relaciona ao Modelo SECl de compartilhamento de conhecimento (Quadro 4).

Quadro 4 - Modelo SECl e Carona Solidária

\begin{tabular}{|l|l|}
\hline \multicolumn{1}{|c|}{ PROCESSO } & \multicolumn{1}{c|}{ CARONA SOLIDÁRIA } \\
\hline Socialização & $\begin{array}{l}\text { A partir da confiança, do relacionamento e do momento proporcionado pela } \\
\text { Carona Solidária, há conversão de conhecimento tácito em tácito, por meio } \\
\text { do compartilhamento de experiências. Experiências pessoais ou profissionais, } \\
\text { incluindo as relacionadas ao ambiente de trabalho. } \\
\text { Esse conhecimento tácito, por exemplo relacionado à organização (como uma } \\
\text { experiência compartilhada sobre determinado comportamento ou atitude da } \\
\text { empresa), pode afetar o comportamento dos indivíduos e gerar mudanças na } \\
\text { forma com que agem perante determinadas situações. }\end{array}$ \\
\hline Externalização & $\begin{array}{l}\text { A conversão do conhecimento tácito em explícito, ocorre por meio da } \\
\text { externalização. Conforme relatado, a iniciativa proporciona a conversa a } \\
\text { respeito de atividades e soluções para problemas da organização, o que no } \\
\text { dia seguinte é executada, gerando resultados visíveis, como a modificação de } \\
\text { um software ou o estabelecimento de um processo novo. }\end{array}$ \\
\hline Combinação & $\begin{array}{l}\text { Os chamados "resultados visíveis" da etapa anterior podem ser combinados } \\
\text { com outros tipos de conhecimentos explícitos da organização, que já não } \\
\text { possuem relação direta com a Carona Solidária. }\end{array}$ \\
\hline Internalização & $\begin{array}{l}\text { A assimilação do conhecimento a partir da prática, ou o conhecimento } \\
\text { explícito sendo convertido em tácito, é outra etapa do processo que não possui } \\
\text { relação direta com a iniciativa. No entanto, a Carona Solidária corrobora com o } \\
\text { melhor aprendizado de uma técnica ou tecnologia (know-how), por exemplo, } \\
\text { a partir do momento em que macetes, detalhes, documentos que auxiliem e } \\
\text { percepções de um indivíduo são compartilhados para outro. }\end{array}$ \\
\hline
\end{tabular}

Fonte: os autores (2015)

Neste contexto, verifica-se que a Carona Solidária se relaciona com a Gestão do Conhecimento em diversos aspectos, principalmente quando se trata do compartilhamento de conhecimento. A iniciativa é uma ação que pode ser promovida por instituições públicas e privadas, que irá impactar não só no meio ambiente e na mobilidade das cidades, mas na gestão do conhecimento na organização.

\section{CONSIDERAÇÕES FINAIS}

A Carona Solidária consiste em uma iniciativa que visa promover a melhoria do meio ambiente, a mobilidade urbana e a colaboração entre indivíduos. Ao ser promovida por organizações, sejam públicas ou privadas, os benefícios se estendem e impactam o desempenho, a produtividade, o clima organizacional, entre outros aspectos.

As organizações intensivas em conhecimento podem explorar essa iniciativa, ao incorporar e implantar na organização. Além do relacionamento fortalecido entre colaboradores e a confiança criada entre os mesmos, a iniciativa facilita o compartilhamento de conhecimentos e colabora com a criação de perfil de trabalhadores colaborativos. Tal aspecto é relevante para organizações que desejam se tornar competitivas em uma sociedade do conhecimento, no qual o fator de produção é o conhecimento.

Como pesquisas futuras, destacamos: aprofundar como a Carona Solidária se relaciona com o Modelo SECl de conversão de conhecimento; estudar a Carona Solidária como prática de gestão do conhecimento nas organizações; e demais estudos acerca da iniciativa que se configura como tendência, a partir do crescente interesse pela preservação do meio ambiente, a colaboração cada vez mais presente na sociedade, o problema da mobilidade urbana nas cidades brasileiras e a acirrada competitividade entre organizações intensivas em conhecimento. 


\section{CONTRIBUTIONS OF SOLIDARITY RIDES IN THE PROCESS OF KNOWLEDGE SHARING}

Currently, more than 85 million cars in Brazil impact mobility in various cities of the country. In addition, issues related to the environment are of increasing interest of society, stimulating initiatives such as solidarity rides (carpooling). In order to contribute to improving the mobility of cities and reduce impacts on the environment, several companies have joined the movement. However, one can formulate a research question that eventually could clarify this statement, which can be characterized as a trend in smarter cities: "Does carpooling consist only of vehicle sharing? Or is it something more than that? " From this research question, the study aimed to verify the impact of carpooling for organizations that promote it, using as reference the case study of an intensive organization in knowledge. As methodological procedure, questionnaires and semi-structures interviews were applied. As a result, it was found that carpooling helps to build relationships among employees, facilitating knowledge sharing, developing collaborative profiles, and it also helps improve the organizational environment which, in turn, affects the retention of talent in organizations.

Keywords: Knowledge management. Knowledge sharing. Solidarity rides.

\section{REFERÊNCIAS}

APLICATIVO oferece carona a amigos das redes sociais. [2015]. Disponível em: $<$ http://cidadeemmovimento. org/aplicativo-oferece-carona-solidaria-para-amigos-comuns-das-redes-sociais/>. Acesso em: 29 ago. 2015.

BARCZAK, R.; DUARTE, F. Impactos ambientais da mobilidade urbana: cinco categorias de medidas mitigadoras. Revista Brasileira de Gestão Urbana, Curitiba, v. 4, n. 1, p. 13-32, jan./jun. 2012.

BRASIL. Conselho Nacional de Saúde. Resolução n. 466, de 12 de dezembro de 2012. [2012]. Diário Oficial [da] República Federativa do Brasil, Poder Executivo, Brasília, DF, 13 jun. 2013. Seção 1, p. 59.

BRASIL. Câmara dos Deputados. COMISSÃO aprova proposta que cria sistema nacional de transporte solidário. Brasília: Câmara dos Deputados, 2014. Disponível em: <http://www2.camara.leg.br/camaranoticias/ noticias/TRANSPORTE-E-TRANSITO/477585-COMISSAO-APROVA-PROPOSTA-QUE-CRIA-SISTEMA-NACIONALDE-TRANSPORTE-SOLIDARIO.html>. Acesso em: 30 ago. 2015.

CHOO, C. W. A organização do conhecimento: como as organizações usam a informação para criar significado, construir conhecimento e tomar decisões. São Paulo: Senac São Paulo, 2003.

DAVENPORT, T.H.; PRUSAK, L. Conhecimento empresarial: como as organizações gerenciam o seu capital intelectual. 15. ed. Rio de Janeiro: Elsevier, 2003.

DICIONÁRIO de português online: significado de carona. Disponível em: <http://michaelis.uol.com.br/ moderno/portugues/index.php?lingua=portugues-portugues\&palavra=carona $>$. Acesso em: 30 ago. 2015.

DIMITRAKOPOULOS, G.; PANAGIOTIS, D.; KOUTRA, V. Intelligent management functionality for improving transportation efficiency by means of the car pooling concept. IEEE transactions on intelligent transportation systems, v. 13, n. 2, 2012. Disponível em: <http://goo.gl/ntmq2G >. Acesso em: 30 ago. 2015.

FEDERAÇÃO NACIONAL DA DISTRIBUIÇÃO DE VEÍCULOS AUTOMOTORES (FENABRAVE). Anuário 2014: o desempenho da distribuição automotiva no Brasil. [2015]. Disponível em: <http://www3.fenabrave.org. br:8082/plus/modulos/listas/index.php?tac=indices-e-numeros\&idtipo=6\&layout=indices-e-numeros $>$. Acesso em: 21 ago. 2015.

HANSEN, M. T. Colaboração: o segredo dos grandes líderes para evitar armadilhas, promover a união e conseguir excelentes resultados. Rio de Janeiro: Elsevier, 2010.

INSTITUTO BRASILEIRO DE GEOGRAFIA E ESTATÍSTICA (IBGE). População do Brasil. 2015. Disponível em: <http://www.ibge.gov.br/apps/populacao/projecao/>. Acesso em: 29 ago. 2015.

JORDÃO, C. Carona, uma saída inteligente. [S.I.]: Planeta Sustentável, 2012. Disponível em: <http:// planetasustentavel.abril.com.br/noticia/atitude/site-carona-veiculos-premio-mobilidade-urbana-690558. 
shtml>. Acesso em: 29 ago. 2015.

MARTINS, J. 6 dicas para reter talentos na sua empresa. [2014]. Disponível em: <http://revistapegn.globo. com/Colunistas/Jairo-Martins/noticia/2014/05/6-dicas-para-reter-talentos-na-sua-empresa.html>. Acesso em: 20 ago. 2015.

MELHORES aplicativos para pedir carona. Disponível em: <http://www.techtudo.com.br/kits/melhoresaplicativos-para-pedir-carona.html>. Acesso em: 30 ago. 2015.

NONAKA, I.; KONNO, N. The concept of "Ba": building a foundation for knowledge creation. California Management Review, v. 40, n. 3, p. 40-54, Spring, 1998.

NONAKA, Ikujiro; TAKEUCHI, Hirotaka. Criação de conhecimento na empresa: como as empresas japonesas geram a dinâmica da inovação. Rio de Janeiro: Elsevier, 1997.

OLIVEIRA, S. C. de. Educação ambiental para promoção da saúde com trânsito solidário. 2013. Dissertação (Mestrado em Serviços de Saúde Pública) - Faculdade de Saúde Pública da Universidade de São Paulo, São Paulo, 2013. Disponível em: <http://www.teses.usp.br/teses/disponiveis/6/6135/tde-02042013-095943/pt-br. php>. Acesso em: 30 ago. 2015.

POPULAÇÃO se organiza para promover carona solidária durante greve do transporte público em Florianópolis. Diário Catarinense, Florianópolis, 10 jun. 2013. Disponível em: <http://diariocatarinense.clicrbs. com.br/sc/geral/noticia/2013/06/populacao-se-organiza-para-promover-carona-solidaria-durante-greve-dotransporte-publico-em-florianopolis-4165362.html>. Acesso em: 30 ago. 2015.

PROBST, G.; RAUB, S.; ROMHARDT, K. Gestão do conhecimento: os elementos construtivos do sucesso. Porto Alegre: Bookman, 2002.

SANTOS, G.; BEHRENDT, H.; TEYTELBOYM, A. Part II: policy instruments for sustainable road transport. Research in transportation economics, v. 28, 2010. Disponível em: <http://goo.gl/uvV9vf>. Acesso em: 30 ago. 2015.

SENGE, Peter M. A quinta disciplina: arte e prática da organização que aprende. 23. ed. Rio de Janeiro: BestSeller, 2008.

SHARECAR: carona solidária é alternativa para o dia a dia. [2015]. Disponível em: <https://www.serpro.gov.br/ noticias/noticias-2015/sharecar-carona-solidaria-e-alternativa-para-o-dia-a-dia>. Acesso em: 29 ago. 2015.

SILVA, D. B. L. da. A formação do capital social baseada em organizações intensivas em conhecimento como fator de desenvolvimento local sustentável: estudo de caso de uma associação de empresas de tecnologia. 2010. Dissertação (Mestrado) - Universidade Federal de Santa Catarina, Florianópolis.

SVEIBY, K. E. A knowledge-based theory of the firm to guide in strategy formulation. Journal of intellectual capital, v. 2, n. 4, p. 344-358, 2001.

TAKEUCHI, Hirotaka; NONAKA, Ikujiro. Gestão do conhecimento. Porto Alegre: Bookman, 2008.

TIWANA, A. The Knowledge Management Toolkit. Orchestrating IT, Strategy and Knowledge Platforms. [S.I.]: Prentice Hall PTR, 2002.

WILSON, J.; GOODMAN, P.; CRONIN, M. Group Learning. Academy of Management Review, New York, v. 32 , n. 4, p. 1041-1059, 2007.

YOUSAF, Jamal et al. Generalized multipath planning model for ride-sharing systems. Frontiers of computer science, v. 8, n. 1, 2014. Disponível em: <http://goo.gl/aBDT3a>. Acesso em: 30 ago. 2015. 


\section{APÊNDICE A - RELAÇÃO ENTRE CARRO X HABITANTES POR ESTADO}

\begin{tabular}{|c|c|c|c|c|}
\hline REGIÃO/ESTADO & HABITANTES & CARROS & PESSOA/CARRO & CARRO / KM ${ }^{2}$ \\
\hline NORTE & 17.231 .027 & 4.297 .820 & 4,00 & \\
\hline $\begin{array}{c}\text { Acre } \\
\left(164.123 \mathrm{~km}^{2}\right) \\
\end{array}$ & $\begin{array}{c}790.101 \\
\left(4,47 \mathrm{hab} / \mathrm{km}^{2}\right) \\
\end{array}$ & 223.550 & 3,53 & 1,36 \\
\hline $\begin{array}{c}\text { Amapá } \\
\left(142.828 \mathrm{~km}^{2}\right)\end{array}$ & $\begin{array}{c}750.912 \\
\left(4,69 \mathrm{hab} / \mathrm{km}^{2}\right) \\
\end{array}$ & 164.945 & 4,55 & 1,15 \\
\hline $\begin{array}{c}\text { Amazonas } \\
\left(1.559 .148 \mathrm{~km}^{2}\right) \\
\end{array}$ & $\begin{array}{c}3.873 .743 \\
\left(2,23 \mathrm{hab} / \mathrm{km}^{2}\right) \\
\end{array}$ & 755.763 & 5,1 & 0,48 \\
\hline $\begin{array}{c}\text { Pará } \\
\left(1.247 .954 \mathrm{~km}^{2}\right)\end{array}$ & $\begin{array}{c}8.073 .924 \\
\left(6,07 \mathrm{hab} / \mathrm{km}^{2}\right)\end{array}$ & 1.585 .786 & 5,09 & 1,27 \\
\hline $\begin{array}{c}\text { Rondônia } \\
\left(237.590 \mathrm{~km}^{2}\right) \\
\end{array}$ & $\begin{array}{c}1.748 .531 \\
\left(6,58 \mathrm{hab} / \mathrm{km}^{2}\right) \\
\end{array}$ & 816.943 & 2,14 & 3,43 \\
\hline $\begin{array}{c}\text { Roraima } \\
\left(224.303 \mathrm{~km}^{2}\right)\end{array}$ & $\begin{array}{c}496.936 \\
\left(2,01 \mathrm{hab} / \mathrm{km}^{2}\right)\end{array}$ & 178.817 & 2,77 & 0,79 \\
\hline $\begin{array}{c}\text { Tocantins } \\
\left(277.720 \mathrm{~km}^{2}\right) \\
\end{array}$ & $\begin{array}{c}1.496 .880 \\
\left(4,98 \mathrm{hab} / \mathrm{km}^{2}\right) \\
\end{array}$ & 572.016 & 2,61 & 2,05 \\
\hline NORDESTE & 56.186 .190 & 14.257 .276 & 3,94 & \\
\hline $\begin{array}{c}\text { Alagoas } \\
\left(27.774 \mathrm{~km}^{2}\right)\end{array}$ & $\begin{array}{c}3.321 .730 \\
\left(112,33 \mathrm{hab} / \mathrm{km}^{2}\right)\end{array}$ & 671.607 & 4,94 & 24,18 \\
\hline $\begin{array}{c}\text { Bahia } \\
\left(564.733 \mathrm{~km}^{2}\right) \\
\end{array}$ & $\begin{array}{c}15.126 .371 \\
\left(24,82 \mathrm{hab} / \mathrm{km}^{2}\right)\end{array}$ & 3.424 .742 & 4,41 & 6,06 \\
\hline $\begin{array}{c}\text { Ceará } \\
\left(148.886 \mathrm{~km}^{2}\right)\end{array}$ & $\begin{array}{c}8.842 .791 \\
\left(56,76 \mathrm{hab} / \mathrm{km}^{2}\right)\end{array}$ & 2.596 .621 & 3,40 & 17,44 \\
\hline $\begin{array}{c}\text { Maranhão } \\
\left(331.936 \mathrm{~km}^{2}\right)\end{array}$ & $\begin{array}{c}6.850 .884 \\
\left(19,81 \mathrm{hab} / \mathrm{km}^{2}\right)\end{array}$ & 1.345 .427 & 5,09 & 4,05 \\
\hline $\begin{array}{c}\text { Paraíba } \\
\left(56.469 \mathrm{~km}^{2}\right)\end{array}$ & $\begin{array}{c}3.943 .885 \\
\left(66,70 \mathrm{hab} / \mathrm{km}^{2}\right) \\
\end{array}$ & 1.036 .041 & 3,80 & 18,34 \\
\hline $\begin{array}{l}\text { Pernambuco } \\
\left(98.149 \mathrm{~km}^{2}\right) \\
\end{array}$ & $\begin{array}{c}9.277 .727 \\
\left(89,62 \mathrm{hab} / \mathrm{km}^{2}\right)\end{array}$ & 2.569 .142 & 3,61 & 26,17 \\
\hline $\begin{array}{c}\text { Piauí } \\
\left(251.611 \mathrm{~km}^{2}\right)\end{array}$ & $\begin{array}{c}3.194 .718 \\
\left(12,40 \mathrm{hab} / \mathrm{km}^{2}\right)\end{array}$ & 947.605 & 3,37 & 3,76 \\
\hline $\begin{array}{l}\text { Rio Grande do Norte } \\
\left(52.811 \mathrm{~km}^{2}\right)\end{array}$ & $\begin{array}{c}3.408 .510 \\
\left(59,99 \mathrm{hab} / \mathrm{km}^{2}\right) \\
\end{array}$ & 1.043 .508 & 3,26 & 19,75 \\
\hline $\begin{array}{c}\text { Sergipe } \\
\left(21.918 \mathrm{~km}^{2}\right)\end{array}$ & $\begin{array}{c}2.219 .574 \\
\left(94,36 \mathrm{hab} / \mathrm{km}^{2}\right)\end{array}$ & 622.583 & 2,12 & 28,40 \\
\hline SUDESTE & 85.115 .623 & 42.756 .172 & 1,99 & \\
\hline $\begin{array}{l}\text { Espírito Santo } \\
\left(46.096 \mathrm{~km}^{2}\right)\end{array}$ & $\begin{array}{c}3.885 .049 \\
\left(76,25 \mathrm{hab} / \mathrm{km}^{2}\right)\end{array}$ & 1.685 .304 & 2,30 & 36,56 \\
\hline $\begin{array}{l}\text { Minas Gerais } \\
\left(586.519 \mathrm{~km}^{2}\right) \\
\end{array}$ & $\begin{array}{c}20.734 .097 \\
\left(33,41 \mathrm{hab} / \mathrm{km}^{2}\right) \\
\end{array}$ & 9.437 .008 & 2,19 & 16,08 \\
\hline $\begin{array}{c}\text { Rio de Janeiro } \\
\left(43.777 \mathrm{~km}^{2}\right)\end{array}$ & $\begin{array}{c}16.461 .173 \\
\left(365,23 \mathrm{hab} / \mathrm{km}^{2}\right) \\
\end{array}$ & 5.915 .612 & 2,78 & 135,13 \\
\hline $\begin{array}{c}\text { São Paulo } \\
\left(248.222 \text { km²) }^{2}\right.\end{array}$ & $\begin{array}{c}44.035 .304 \\
\left(166,23 \mathrm{hab} / \mathrm{km}^{2}\right)\end{array}$ & 25.718 .248 & 1,71 & 103,60 \\
\hline SUL & 29.016 .114 & 17.380 .005 & 1,66 & \\
\hline
\end{tabular}




\begin{tabular}{|c|c|c|c|c|}
\hline $\begin{array}{c}\text { Paraná } \\
\left(199.307 \mathrm{~km}^{2}\right)\end{array}$ & $\begin{array}{c}11.081 .692 \\
\left(52,40 \mathrm{hab} / \mathrm{km}^{2}\right)\end{array}$ & 6.716 .094 & 1,65 & 33,69 \\
\hline $\begin{array}{c}\text { Rio Grande do Sul } \\
\left(281.731 \mathrm{~km}^{2}\right)\end{array}$ & $\begin{array}{c}11.207 .274 \\
\left(37,96 \mathrm{hab} / \mathrm{km}^{2}\right)\end{array}$ & 6.217 .960 & 1,76 & 22,07 \\
\hline $\begin{array}{c}\text { Santa Catarina } \\
\left(95.733 \mathrm{~km}^{2}\right)\end{array}$ & $\begin{array}{c}6.727 .148 \\
\left(65,27 \mathrm{hab} / \mathrm{km}^{2}\right)\end{array}$ & 4.445 .951 & 1,47 & 46,44 \\
\hline $\begin{array}{c}15.219 .608 \\
\text { CENTRO-OESTE }\end{array}$ & $\mathbf{8 . 0 0 9 . 2 1 7}$ & 1,90 & 274,47 \\
\hline $\begin{array}{c}\text { Distrito Federal } \\
\left(5.779 \mathrm{~km}^{2}\right)\end{array}$ & $\begin{array}{c}2.852 .372 \\
\left(444,66 \mathrm{hab} / \mathrm{km}^{2}\right)\end{array}$ & 1.586 .169 & 1,79 & 9,95 \\
\hline $\begin{array}{c}\text { Goiás } \\
\left(340.111 \mathrm{~km}^{2}\right)\end{array}$ & $\begin{array}{c}6.523 .222 \\
\left(17,65 \mathrm{hab} / \mathrm{km}^{2}\right)\end{array}$ & 3.386 .702 & 1,92 & 1,87 \\
\hline $\begin{array}{c}\text { Mato Grosso } \\
\left(903.378 \mathrm{~km}^{2}\right)\end{array}$ & $\begin{array}{c}3.224 .357 \\
\left(3,36 \mathrm{hab} / \mathrm{km}^{2}\right)\end{array}$ & 1.696 .945 & 1,90 & 3,75 \\
\hline $\begin{array}{c}2.619 .657 \\
\left(6,86 \mathrm{hab} / \mathrm{km}^{2}\right)\end{array}$ & 1.339 .401 & 1,95 & \\
\hline
\end{tabular}

Fonte: dos autores (2015), com base em dados obtidos no site da Fenabrave (FEDERAÇÃO, 2015) e IBGE (INSTITUTO, 2014). 